\title{
Multi Objective Optimization of Weld Parameters of Boiler Steel Using Fuzzy Based Desirability Function
}

\author{
M. Satheesh ${ }^{* 1}$ and J. Edwin Raja Dhas ${ }^{2}$ \\ ${ }^{I}$ Dep. of Mechanical Engineering, Noorul Islam Centre for Higher Education, Kumaracoil, Tamil nadu, India \\ ${ }^{2}$ Dep. of Automobile Engineering, Noorul Islam Centre for Higher Education, Kumaracoil, Tamil nadu, India
}

Received 21 June 2013; Accepted 5 January 2014

\begin{abstract}
The high pressure differential across the wall of pressure vessels is potentially dangerous and has caused many fatal accidents in the history of their development and operation. For this reason the structural integrity of weldments is critical to the performance of pressure vessels. In recent years much research has been conducted to the study of variations in welding parameters and consumables on the mechanical properties of pressure vessel steel weldments to optimize weld integrity and ensure pressure vessels are safe. The quality of weld is a very important working aspect for the manufacturing and construction industries. Because of high quality and reliability, Submerged Arc Welding (SAW) is one of the chief metal joining processes employed in industry. This paper addresses the application of desirability function approach combined with fuzzy logic analysis to optimize the multiple quality characteristics (bead reinforcement, bead width, bead penetration and dilution) of submerged arc welding process parameters of SA 516 Grade 70 steels(boiler steel). Experiments were conducted using Taguchi's L27 orthogonal array with varying the weld parameters of welding current, arc voltage, welding speed and electrode stickout. By analyzing the response table and response graph of the fuzzy reasoning grade, optimal parameters were obtained. Solutions from this method can be useful for pressure vessel manufacturers and operators to search an optimal solution of welding condition.
\end{abstract}

Keywords: ANOVA, Desirability, Fuzzy, Orthogonal array, Taguchi

\section{Introduction}

Submerged arc welding (SAW) is a multi-objective, multifactor metal joining technique. SAW process is used widely in the fabrication of pressure vessels, marine vessels, pipelines and offshore structures due to high deposition rate [1]. The quality of a weld joint is greatly influenced by the welding input parameters during the welding process $[2,3]$. Basic parameters of submerged arc welding are: welding current, intensity, voltage, speed of welding, wire diameter, length of wire stickout, thickness and width of welding flux layer and inclination angle of an electrode. These parameters have to be selected and precisely controlled in a judicious manner to achieve weld of desired quality. Weld quality depends on features of bead geometry, mechanicalmetallurgical characteristics of the weld metal and HAZ, and on weld chemistry [4]. The problem faced by the weld operator to control the process input parameters to obtain a good welded joint with the required bead geometry and weld quality with minimal detrimental residual stresses and distortion. Hence these parameters should be selected in a judicious manner to reach the desired target by the area of application of the weldment. Traditionally, it was necessary to determine the weld input parameters for every new welded product to obtain a welded joint with the required

*E-mail address: satheeshudaya@gmail.com

ISSN: 1791-2377 @ 2014 Kavala Institute of Technology. All rights reserved. specifications. To do so, weld input parameters should be chosen by the skill of the engineer or machine operator which is a time-consuming trial and error development effort. In order to overcome this problem, various optimization methods have emerged to define the desired output variables through developing mathematical models to establish the relationship between the input parameters and output variables. Toyofumi et al. [5] and Tsai et al. [6] observed that the optimization values of welding conditions in spiral pipes and process parameters in hardfacing through submerged arc welding process. Tarng and Yang [7] applied Taguchi method to the optimization of the submerged arc welding process. Gunaraj and Murugan [8] applied Response Surface Methodology (RSM) for prediction and optimization of weld bead quality in submerged arc welding of pipes by establishing mathematical models. Keshav Prasad et al. [9] analyzed the effect of microstructure, hardness, and toughness of HSLA steel weld joints by varying heat input of submerged arc welding process. Curvilinear equations [10], linear regression equations [11], multiple regression analysis [12] and Taguchi method [7] have been used to model SAW process.

However, traditional Taguchi technique cannot solve multi-objective optimization problem efficiently and effectively. The most used approach for multi objective problem is to assign weights for every response. To 
overcome these limitations Taguchi based grey relational analysis approach [13] was developed to handle uncertain systematic problem with only partial known information. Tarng et al. [14] applied grey based Taguchi method for optimization submerged arc welding process parameters in hardfacing. In Grey Taguchi approach, all quality features are assumed to be independent. But in actual case, the assumption may deviate. To triumph over this, instead of grey-Taguchi, Pearson and Hotelling developed Principal Component Analysis (PCA). Biswas et al. [15] applied PCA in Taguchi method to optimize the bead geometry of Submerged Arc Weld parameters.

The individual priority weights are required to be assigned to different responses. In practice, these responses may not be of equally importance. Degree of significance of various responses depends on application area and functional requirements of the product. For good joint strength, the weldment should have high degree of penetration depth and to reduce weld metal consumption, it is desired that the weld should have less bead reinforcement and bead width [16]. Also to reduce solidification shrinkage the weldment should have minimum dilution [17]. In general, weld strength is of vital importance. Therefore, priority weight of penetration depth is to be set more compared to bead width bead reinforcement and dilution. Assignment of response priority weights basically depends on the judgment of the decision maker. Change in value of the priority weights yields change in the value of aggregated quality index. Moreover, above mentioned approaches are based on the assumption that responses are uncorrelated. Interdependence of the responses has been assumed negligible while in practice any change in one response remarkably affects another response. Thus, judgment of priority weights in conjunction with assumption of negligible response correlation may lead to vagueness in the solution. To overcome these limitations researches introduced some hybrid methods. Taguchi based Utility theory optimization concept [18] has been applied to predict process parameters of Submerged Arc Welding. Naveen Sait et al. [19] used Taguchi method in combination with desirability function to optimize machining parameters of glass-fibre-reinforced plastic. Genetic algorithm along with Taguchi method was used to optimize parameters of submerged arc welding in the hardfacing process [20] and weld bead geometry in plasma transferred arc hard faced austenitic stainless steel plates [21]. Recently, optimization of machining parameters for the milling operation and optimization of friction welding parameters was carried using particle swarm optimization algorithm [22] was carried out. Ankita Singh et al. [16] investigated Optimization of bead geometry of submerged arc weld using fuzzy based desirability function approach for SAIL Steel, IS 2062. Kumaresh Babu et al. [23] studied the different corrosion behavior of SA 516 Gr. 70 steel in Gas Tungsten Arc Welding. Lin et al. [24] applied the hybrid TaguchiFuzzy logic method for optimization of EDM Process parameters. In this article, application of desirability approach combined with fuzzy logic analysis to optimize the multiple quality characteristics of submerged arc welding process parameters of SA 516 Grade 70 steels.

\section{Desirability Function And Fuzzy Logic Analysis}

\subsection{Desirability function}

Desirability function approach is powerful tools for solving the multiple performance characteristics optimization problems, where all the objectives are attain a definite goal simultaneously. The desirability lies between 0 and 1 and it represents the closeness of a response to its ideal value. If a response falls within the unacceptable intervals, the desirability is 0 , and if a response falls within the ideal intervals or the response reaches its ideal value, the desirability is 1 . Meanwhile, when a response falls within the tolerance intervals but not the ideal interval, or when it fails to reach its ideal value, the desirability lies between 0 and 1 . The more closely the response approaches the ideal intervals or ideal values, the closer the desirability is to 1.The basic idea of this approach is to convert a multiple performance characteristics optimization problem into a single response optimization problem with the objective function of overall desirability. Then the overall desirability function is optimized. The desirability function method was first introduced by Harrington [25], who used the exponential type transformation of response value to its desirability. Kim and Lin [26] presented a more general desirability transformation, which is flexible to the analysts. According to Derringer and Suich [27] approach, one- and two-sided desirability functions can be used depending on whether the response is to be maximized or minimized or has and assigned target value. Let $L_{i}$ and $H_{i}$ be the lower and upper specification limits and $T_{i}$ be the target value of the $i$ th response respectively (such that $L_{i} \leq T_{i} \leq H_{i}$ ). For a response $y_{i}$ with a target value (nominal is best), the individual desirability is defined as Equation (1).

$$
d_{i}=\left\{\begin{array}{l}
0, y_{i}<L_{i} \\
{\left[\left(y_{i}-L_{i}\right) /\left(T_{i}-L_{i}\right)\right]^{s_{i}}, L_{i} \leq y_{i} \leq T_{i}} \\
{\left[\left(H_{i}-y_{i}\right) /\left(H_{i}-T_{i}\right)\right]^{t_{i}}, T_{i} \leq y_{i} \leq H_{i}} \\
0, y_{i}>H_{i}
\end{array}\right.
$$

where the weights $S_{i}$ and $t_{i}$ determine how strictly the target value is desired. If the response $y_{i}$ is at its goal or target, then $d_{i}=1$, and if the response is outside the acceptable region, $d_{i}=0$. The value of $d_{i}$ increases as the "desirability" of the corresponding response increases.

Similarly, we can define one-sided desirability functions for minimizing or maximizing case. For larger the- better problem, the individual desirability is given by Equation (2).

$d_{i}=\left\{\begin{array}{l}0, y_{i}<L_{i} \\ {\left[\left(y_{i}-L_{i}\right) /\left(T_{i}-L_{i}\right)\right]^{s_{i}}, L_{i} \leq y_{i} \leq T_{i}} \\ 1, y_{i}>T_{i}\end{array}\right.$

and for smaller-the-better problem, the individual desirability is calculated as Equation (3)

$d_{i}=\left\{\begin{array}{l}1, y_{i}<T_{i} \\ {\left[\left(H_{i}-y_{i}\right) /\left(H_{i}-T_{i}\right)\right]^{t_{i}}, T_{i} \leq y_{i} \leq H_{i}} \\ 0, y_{i}>H_{i}\end{array}\right.$

The individual desirability values have been accumulated to calculate the overall desirability using the following Equation (4). 


$$
D_{o}=\left(d_{1}^{w_{1}} d_{2}^{w_{2}} \ldots . d_{n}^{W_{n}}\right)^{1 / \sum W_{i}}
$$

Here $D_{o}$ is the overall desirability value, $d_{i}$ is the individual desirability value of $i$ th quality characteristic and $n$ is the total number of responses. $W_{i}$ is the weight for $i$ th attribute. Sum of all attribute weights should be equal to 1. However, overall desirability $D_{o}$ can be treated as equivalent aggregated quality index but the problem arises in assigning priority weights of various responses. Literature showed that previous investigators determined optimal setting of process parameters [28] by maximizing $D_{o}$ in the experimental domain. The results obtained thereof, may be inaccurate because the exact value of priority weight to be assigned to each and individual responses is difficult to predict. Therefore to sort-out these limitations, fuzzy logic approach combine with desirability function has been introduced. The flow chart of the fuzzy logic controller coupled with desirability function method used in the study is shown in Figure 1.

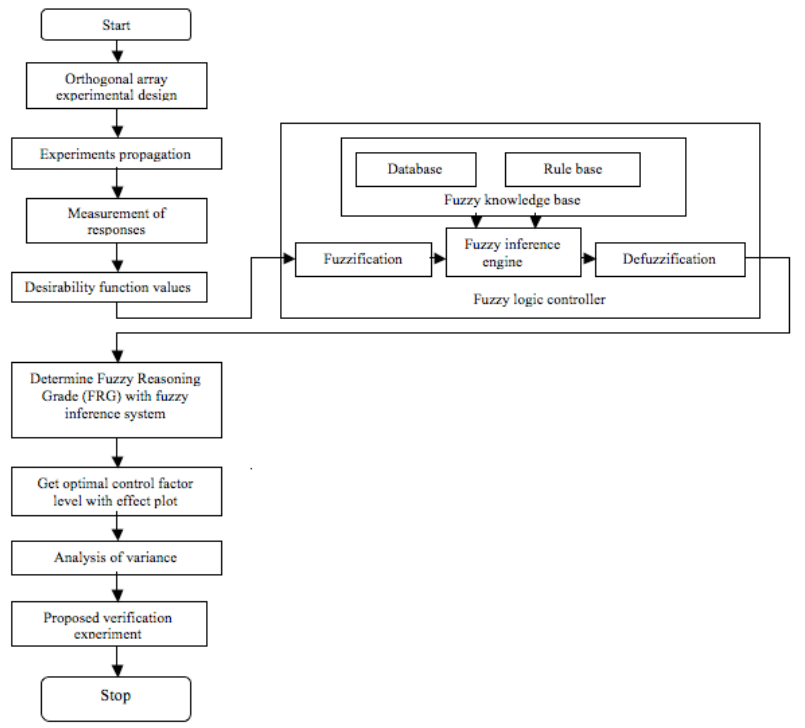

Fig. 1. Flowchart of the fuzzy logic controller coupled with desirability function approach

\subsection{Fuzzy logic analysis}

The theory of fuzzy logic was initiated by Zadeh [29]. It is a way of representing information that mimics human reasoning about information [30]. The most interesting fact about fuzzy logic is that fuzzy inferences make it possible to deduce a proposition similar to the consequence from some proposition that is similar to the antecedent [31] (Dubois and Prade 1980). Fuzzy controllers and fuzzy reasoning [32] have found particular applications in very complex industrial systems that cannot be modeled precisely even under various assumptions and approximations. The fuzzy logic approach combines with Taguchi techniques has been applied to optimize multiple objectives in machining process [33]. The fuzzy system is composed of a fuzzifier, an inference engine, a data base, a rule base, and defuzzifier. In the study, the fuzzifier initially uses membership functions (MF) to convert the crisp inputs into fuzzy sets. Once all crisp input values have been fuzzified into their respective linguistic values, the inference engine will access the fuzzy rule base of the fuzzy expert system to derive linguistic values for the intermediate as well as the output linguistic variables. The fuzzy rule base consists of a group of if-then control rules with the four desirability function values, $x_{1}, x_{2}, x_{3}$ and $x_{4}$, and one multi response output $y$, that is:

Rule 1: if $x_{1}$ is $A_{1}$ and $x_{2}$ is $B_{1}$ and $x_{3}$ is $C_{1}$ and $x_{4}$ is $\mathrm{D}_{1}$ then $y$ is $E_{1}$ else

Rule 2: if $x_{1}$ is $A_{2}$ and $x_{2}$ is $B_{2}$ and $x_{3}$ is $C_{2}$ and $x_{4}$ is $\mathrm{D}_{2}$ then $y$ is $E_{2}$ else

.........................................

Rule $n$ : if $x_{1}$ is $A_{n}$ and $x_{2}$ is $B_{n}$ and $x_{3}$ is $C_{n}$ and $x_{4}$ is $\mathrm{D}_{n}$ then $y$ is $E_{n}$.

$A_{i}, B_{i}, C_{i}$ and $D_{i}$ are fuzzy subsets defined by the corresponding membership functions, i.e. $\mu_{A_{i}}, \mu_{B_{i}}, \mu_{C_{i}}$ and $\mu_{D_{i}}$. Suppose $x_{1}, x_{2}, x_{3}$ and $x_{4}$ are the four desirability values, the membership function of the multi-response output $y$ can $b$ be expressed as Equation (5):

$$
\begin{aligned}
\mu_{E_{o}}(y)= & \left(\mu_{A_{1}}\left(x_{1}\right) \wedge \mu_{B_{1}}\left(x_{2}\right) \wedge \mu_{C_{1}}\left(x_{3}\right) \wedge \mu_{D_{1}}\left(x_{4}\right) \wedge \mu_{E_{1}}(y)\right) \ldots . . \vee \\
& \left(\mu_{A_{n}}\left(x_{1}\right) \wedge \mu_{B_{n}}\left(x_{2}\right) \wedge \mu_{C_{n}}\left(x_{3}\right) \wedge \mu_{D_{n}}\left(x_{4}\right) \wedge \mu_{E_{1}}(y)\right)
\end{aligned}
$$

Where $\wedge$ and $\vee$ are the minimum and maximum operation respectively. The above equation is illustrated in Figure 2.

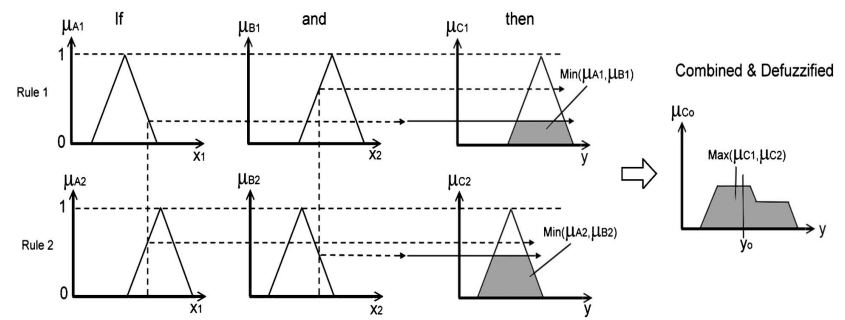

Fig. 2. Mamdani implication methods with fuzzy controller operations.

Finally, a centroid defuzzification method is adopted to transform the fuzzy multi-response output $\mu_{c_{o}}(y)$ into a non- fuzzy value $y_{o}$, Equation (6).

$y_{o}=\frac{\sum y \mu_{C_{o}}(y)}{\sum \mu_{C_{o}}(y)}$

\section{Experimental Methods}

The experiment was conducted on CU-BUILT (Maker: $\mathrm{Cu}$ Built Engineers, India) DC electrode positive welding machine at Precision Storage Vessels Ltd, Kanyakumari, India. The test pieces of size $250 \mathrm{~mm} \times 200 \mathrm{~mm} \times 8 \mathrm{~mm}$ were cut from SA 516 Grade 70 steel plate and its surfaces were ground to remove oxide scale and dirt before cladding. Electrode wire of diameter $2.5 \mathrm{~mm}$ (AWS A/S 5.17:EL8) was used for experimentation. Flux (EN 760SAAR 1) of grain size $0.2-1.2 \mathrm{~mm}(\mathrm{SiO} 2+\mathrm{TiO} 218 \%, \mathrm{~A} 12 \mathrm{O} 3+\mathrm{MnO} 2$ $61 \%, \mathrm{CaO}+\mathrm{MgO} 3 \%, \mathrm{CaF} 211 \%$ ) used for welding. The flux was baked for 2 hours at $523 \mathrm{~K}$ before use. The operating ranges of the parameters are chosen from 
American Welding Society handbook. Selections of welding parameters of each level are shown in Table 1. Chemical composition of the work piece and electrode is shown in Table 2. The experimental setup used consists of a traveling carriage with a table for supporting the specimens. The nozzle was held stationary in a frame mounted above the work table, and it is provided with an attachment for up and down movement to adjust nozzle-to-plate distance. Photograph of the experimental setup is shown in Figure 3.

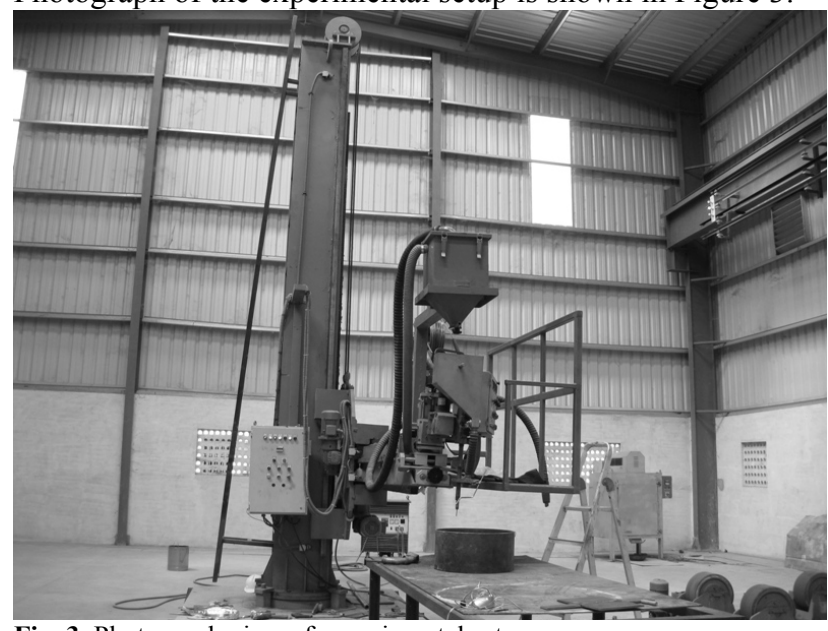

Fig. 3. Photograph view of experimental setup

Table 1. Process parameters and their levels chosen for experiments

\begin{tabular}{c|c|c|c|c}
\hline No & Process parameters & Level & Level & Level \\
& & $\mathbf{1}$ & $\mathbf{2}$ & $\mathbf{3}$ \\
\hline 1 & Welding current (I), amperes & 275 & 325 & 400 \\
2 & Arc voltage (V), volts & 28 & 32 & 36 \\
3 & Welding speed (S), cm/min & 16 & 19 & 22 \\
4 & Electrode extension (E), mm & 25 & 30 & 35 \\
\hline
\end{tabular}

Table 2. Chemical composition of the base metal and the electrode

\begin{tabular}{c|c|c|c|c|c|c|c|c|c|c|c}
\hline \multirow{2}{*}{ Materials } & \multicolumn{10}{c|}{ Chemical composition (mass \%) } \\
\cline { 2 - 12 } & Mn & $\mathrm{C}$ & $\mathrm{P}$ & $\mathrm{S}$ & $\mathrm{Si}$ & $\mathrm{Al}$ & $\mathrm{Cu}$ & $\mathrm{Ni}$ & $\mathrm{Cr}$ & $\mathrm{Ti}$ & $\mathrm{Mo}$ \\
\hline SA516Gr. & 1.1 & 0.2 & 0.01 & 0.00 & 0.2 & 0.05 & 0.0 & 0.0 & 0.0 & 0.00 & 0.00 \\
$\mathbf{7 0}$ & 4 & 2 & 9 & 8 & 4 & 4 & 2 & 1 & 2 & 4 & 2 \\
EL-8 & 0.5 & 0.1 & 0.03 & - & 0.0 & - & 0.1 & - & - & - & - \\
\hline
\end{tabular}

Weld samples of size $10 \mathrm{~mm}$ (width) are cut from the centre of the weld specimen. The transverse face of the samples were polished using mesh size of 245, 425 and 515 (grade 1/0, 2/0, and 3/0) Sianor B 1600 sandpaper. The specimens are further polished using aluminum oxide initially and then by utilizing diamond paste and velvet cloth in a polishing machine. The polished specimens after cleaning with alcohol are macro-etched using $2 \% \mathrm{Nital}(98 \%$ nitric acid $+2 \%$ alcohol) solution to view the geometries of the weld bead. Several significant parameters, such as bead reinforcement, bead width, bead penetration and dilution have been measured as shown in Figure 4. Each macroetched sample image is scanned using an Epson Scan jet with $2400 \mathrm{X} 4800$ DPI resolutions and 1:1 scale is shown in Figure 5. The bead geometries (reinforcement, width and penetration) were measured using the Adobe acrobatmeasuring tool at $500 \%$ magnification. The measured dimensions were compared with those obtained using a Toolmakers' microscope, to check the accuracy of measurement. With the help of a digital planimeter, the areas of the parent metal melted and the metal forming the reinforcement were measured. Percentage of dilution is calculated as $\mathrm{D}=[\mathrm{AP} /(\mathrm{AP}+\mathrm{AR})] \times 100$. The observed values from the specimens are given in Table 3 .

Table 3. Experimental results of Taguchi orthogonal arrays and their performance evaluation

\begin{tabular}{|c|c|c|c|c|c|c|c|c|}
\hline \multirow{2}{*}{ Experimental run } & \multicolumn{4}{|c|}{ Process variables } & \multicolumn{4}{|c|}{$\begin{array}{c}\text { Dimensions of weld bead } \\
\text { Geometry }\end{array}$} \\
\hline & I & V & $\mathbf{S}$ & E & $\mathbf{R}$ & $\mathbf{W}$ & $\mathbf{P}$ & D \\
\hline 1 & 1 & 1 & 1 & 1 & 1.27 & 15.62 & 4.06 & 15.73 \\
\hline 2 & 1 & 1 & 2 & 2 & 1.02 & 17.18 & 3.81 & 17.9 \\
\hline 3 & 1 & 1 & 3 & 3 & 1.28 & 19.22 & 4.12 & 19.6 \\
\hline 4 & 1 & 2 & 1 & 2 & 1.42 & 16.66 & 4.32 & 18.12 \\
\hline 5 & 1 & 2 & 2 & 3 & 1.62 & 17.73 & 4.57 & 20.1 \\
\hline 6 & 1 & 2 & 3 & 1 & 1.93 & 15.45 & 4.83 & 17.53 \\
\hline 7 & 1 & 3 & 1 & 3 & 1.83 & 17.45 & 4.88 & 19.34 \\
\hline 8 & 1 & 3 & 2 & 1 & 2.38 & 15.28 & 5.84 & 16.37 \\
\hline 9 & 1 & 3 & 3 & 2 & 2.54 & 16.45 & 6.10 & 19.2 \\
\hline 10 & 2 & 1 & 1 & 2 & 1.08 & 17.4 & 3.98 & 18.8 \\
\hline 11 & 2 & 1 & 2 & 3 & 1.32 & 18.7 & 4.06 & 21.2 \\
\hline 12 & 2 & 1 & 3 & 1 & 1.34 & 16.3 & 4.32 & 19.02 \\
\hline 13 & 2 & 2 & 1 & 3 & 1.82 & 18.15 & 4.57 & 21.14 \\
\hline 14 & 2 & 2 & 2 & 1 & 1.89 & 15.82 & 5.14 & 18.3 \\
\hline 15 & 2 & 2 & 3 & 2 & 1.92 & 17.32 & 4.83 & 20.96 \\
\hline 16 & 2 & 3 & 1 & 1 & 2.29 & 14.45 & 5.59 & 17.41 \\
\hline 17 & 2 & 3 & 2 & 2 & 2.42 & 16.59 & 5.84 & 19.71 \\
\hline 18 & 2 & 3 & 3 & 3 & 2.43 & 18.02 & 6.20 & 22.4 \\
\hline 19 & 3 & 1 & 1 & 3 & 1.33 & 20.33 & 4.32 & 23.1 \\
\hline 20 & 3 & 1 & 2 & 1 & 1.51 & 16.71 & 4.57 & 19.24 \\
\hline 21 & 3 & 1 & 3 & 2 & 1.52 & 18.24 & 4.61 & 23.2 \\
\hline 22 & 3 & 2 & 1 & 1 & 1.78 & 16.31 & 6.04 & 18.19 \\
\hline 23 & 3 & 2 & 2 & 2 & 1.81 & 17.67 & 5.17 & 21.4 \\
\hline 24 & 3 & 2 & 3 & 3 & 1.94 & 18.94 & 5.08 & 21.57 \\
\hline 25 & 3 & 3 & 1 & 2 & 1.96 & 17.29 & 5.88 & 23.37 \\
\hline 26 & 3 & 3 & 2 & 3 & 2.22 & 18.67 & 5.68 & 21.87 \\
\hline 27 & 3 & 3 & 3 & 1 & 2.77 & 16.22 & 7.19 & 22.6 \\
\hline
\end{tabular}

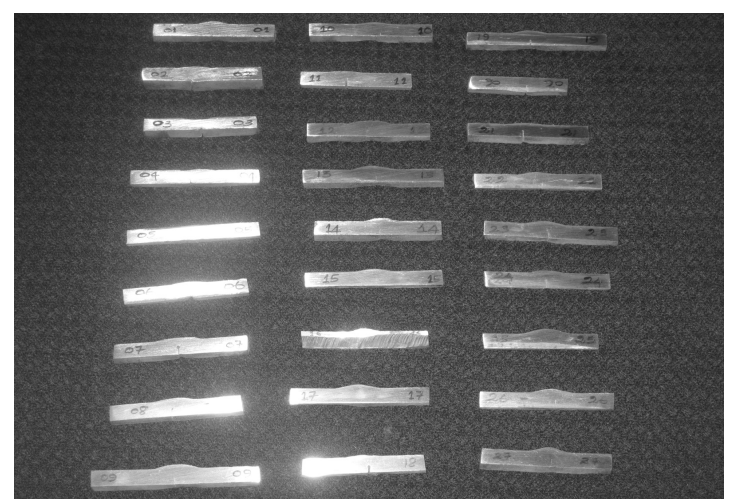

Fig. 4. Photographic view of weld samples 


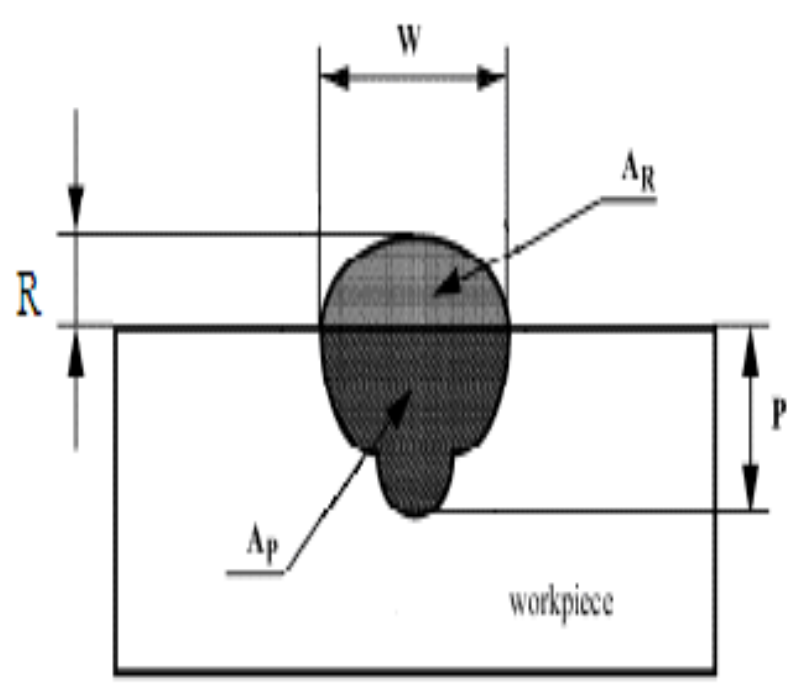

Fig. 5. Cross section of a typical weld bead

Where

$\mathrm{W}=$ Weld bead width in $\mathrm{mm}, \mathrm{R}=$ Weld bead height in $\mathrm{mm}$, $\mathrm{P}=$ Weld bead penetration in $\mathrm{mm}, \mathrm{A}_{\mathrm{P}}=$ Area of penetration in $\mathrm{mm}^{2}$ and $\mathrm{A}_{\mathrm{R}}=$ Area of reinforcement in $\mathrm{mm}^{2}$

\section{Results and Discussion}

\subsection{Orthogonal array experiment}

In the present study, the interaction between the welding parameters is neglected. Therefore, degrees of freedom due to the four sets of three-level welding process parameters were analyzed. The degrees of freedom for the orthogonal array should be greater than or at least equal to those for the process parameters. In this study, an $\mathrm{L}_{27}$ orthogonal array with four columns and 27 rows was used. This array has 8 degrees of freedom and it can handle three-level process parameters. Twenty-seven experiments were required to study the welding parameters using $\mathrm{L}_{27}$ orthogonal array. The experimental layout for the welding process parameters using the $\mathrm{L}_{27}$ orthogonal array is shown in Table 3 .

\subsection{Multi objective Optimization}

Since the traditional Taguchi method deals with single response, it is necessary to convert four objectives into single performance index. Therefore, desirability values have been computed for the selected bead geometry parameters. In this calculation, linear desirability function has been chosen (desirability function index unity). While calculating various desirability values; a Higher-the-better (HB) criterion has been selected for bead penetration (Equation 2), whereas a Lower-the better (LB) criterion has been selected for bead reinforcement, bead width and dilution (Equation 3). These selections have been based on functional requirements of the weldment when subjected to application filed. The calculated individual desirability values corresponding to each parameter is shown in Table 4. In order to calculate overall desirability, a fuzzy inference system has been proposed to obtain individual response desirability values. These values have been treated as four inputs and fuzzy reasoning grade (FRG) as output. The optimal process setting may be evaluated by maximizing this FRG.
Table 4. Individual desirability values of bead geometry parameters and FRG

\begin{tabular}{|c|c|c|c|c|c|}
\hline \multirow[t]{2}{*}{ Sl.No } & \multicolumn{4}{|c|}{$\begin{array}{c}\text { Individual desirability values } \\
\text { of bead geometry } \\
\text { parameters }\end{array}$} & \multirow{2}{*}{$\begin{array}{c}\text { Fuzzy } \\
\text { Reasoning } \\
\text { Grade (FRG) }\end{array}$} \\
\hline & $\mathrm{R}$ & $\mathrm{W}$ & $\mathrm{P}$ & $\mathrm{D}$ & \\
\hline 1 & 0.85 & 0.80 & 0.08 & 1.00 & 0.726 \\
\hline 2 & 1.00 & 0.54 & 0.00 & 0.72 & 0.679 \\
\hline 3 & 0.85 & 0.19 & 0.09 & 0.49 & 0.395 \\
\hline 4 & 0.77 & 0.62 & 0.15 & 0.69 & 0.603 \\
\hline 5 & 0.66 & 0.44 & 0.23 & 0.43 & 0.450 \\
\hline 6 & 0.48 & 0.83 & 0.30 & 0.76 & 0.659 \\
\hline 7 & 0.53 & 0.49 & 0.32 & 0.53 & 0.455 \\
\hline 8 & 0.22 & 0.86 & 0.60 & 0.92 & 0.731 \\
\hline 9 & 0.13 & 0.66 & 0.68 & 0.55 & 0.561 \\
\hline 10 & 0.97 & 0.50 & 0.05 & 0.60 & 0.644 \\
\hline 11 & 0.83 & 0.28 & 0.08 & 0.28 & 0.394 \\
\hline 12 & 0.81 & 0.69 & 0.15 & 0.57 & 0.617 \\
\hline 13 & 0.54 & 0.37 & 0.23 & 0.29 & 0.330 \\
\hline 14 & 0.50 & 0.77 & 0.39 & 0.66 & 0.629 \\
\hline 15 & 0.49 & 0.51 & 0.30 & 0.32 & 0.352 \\
\hline 16 & 0.27 & 1.00 & 0.53 & 0.78 & 0.761 \\
\hline 17 & 0.20 & 0.64 & 0.60 & 0.48 & 0.522 \\
\hline 18 & 0.19 & 0.39 & 0.71 & 0.13 & 0.344 \\
\hline 19 & 0.82 & 0.00 & 0.15 & 0.04 & 0.244 \\
\hline 20 & 0.72 & 0.62 & 0.23 & 0.54 & 0.551 \\
\hline 21 & 0.71 & 0.36 & 0.24 & 0.02 & 0.353 \\
\hline 22 & 0.56 & 0.68 & 0.66 & 0.68 & 0.644 \\
\hline 23 & 0.55 & 0.45 & 0.40 & 0.26 & 0.393 \\
\hline 24 & 0.47 & 0.24 & 0.38 & 0.24 & 0.314 \\
\hline 25 & 0.46 & 0.52 & 0.61 & 0.00 & 0.429 \\
\hline 26 & 0.31 & 0.28 & 0.55 & 0.20 & 0.322 \\
\hline 27 & 0.00 & 0.70 & 1.00 & 0.10 & 0.407 \\
\hline
\end{tabular}

In this study, the most popular defuzzification method is the centroid calculation, which returns the centre of area under the curve. The defuzzifier can convert the fuzzy value into non-fuzzy value which is called as fuzzy reasoning grade. The MF adopts in this is trapezoidal MF which has a flat top and really is just a truncated triangle curve. There are three fuzzy subsets are assigned in the desirability values for bead reinforcement, bead width, bead penetration and dilution: small, middle and large as shown in Figure 6. Nine fuzzy subsets are assigned in the multi-response output: tiny, very small, small, small-medium, medium, medium-large, large, very large, and huge (Figure 7). Various degrees of membership of the fuzzy sets are calculated based on the values of $x_{1}, x_{2}, x_{3}, x_{4}$ and $y$. Thus, straightaway 81 fuzzy rules are derived based on the larger $\mathrm{S} / \mathrm{N}$ ratio is the better process response. A fuzzy multi-response output is produced from these rules by taking the max-min inference operation.

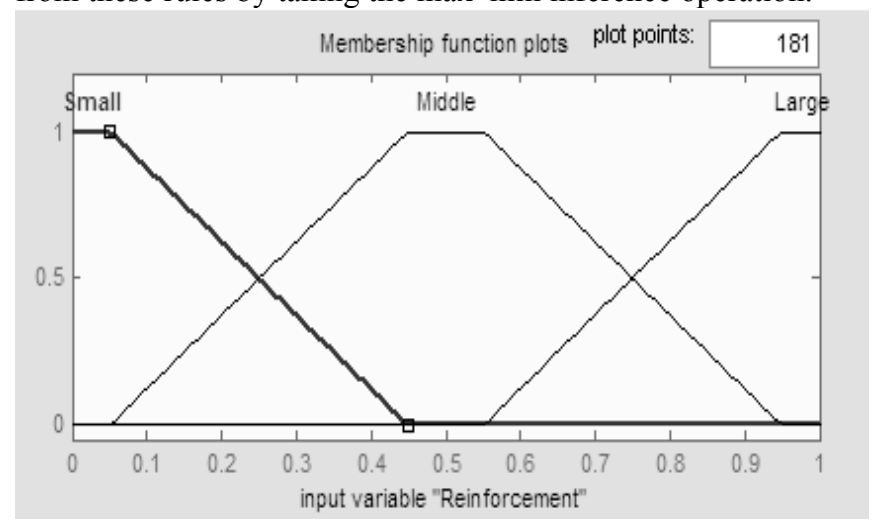

Fig. 6. Membership functions of input variable 
M. Satheesh and J. Edwin Raja Dhas/Journal of Engineering Science and Technology Review 7 (1) (2014) 29 - 36

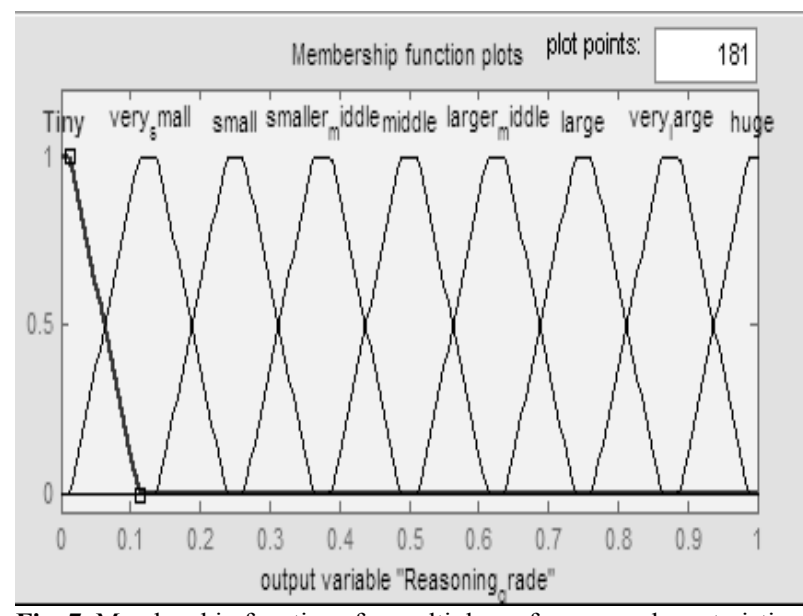

Fig. 7. Membership functions for multiple performance characteristics

Based on the above discussion, the larger the fuzzy reasoning grade, the better is the multiple process responses. Table 4 shows the experimental results for the fuzzy reasoning grade using the experimental layout. Thus, the multi-criteria optimization problem has been transformed into a single objective optimization problem using the combination of desirability function fuzzy logic analyses. The sequence with largest fuzzy reasoning grade indicates it's the most closest to the desired values of the quality characteristics. The fuzzy analysis procedure for the optimal conditions is graphically presented in Figure 8, in which rows represent the 81 rules, and columns are the four inputs and one output variable. The locations of trapezoidal indicates the determined fuzzy sets for each input and output value. The reinforcement of the darkened area in each trapezoidal corresponds to the fuzzy membership value for that fuzzy set.

To determine the optimal process parameters, the effect of each weld process parameter on the ratio at different levels can be separated out since the experimental design is orthogonal. To obtain the effect of each control factor on each quality characteristic for each level, the ratios with same level of control factor are averaged for 27 experiments. From Table 5, it is concluded parameter combination $I_{1} V_{1} S_{1} E_{1}$ has the best performance for all the quality characteristics. The response plot for the overall fuzzy reasoning grade is represented graphically in Figure 9.

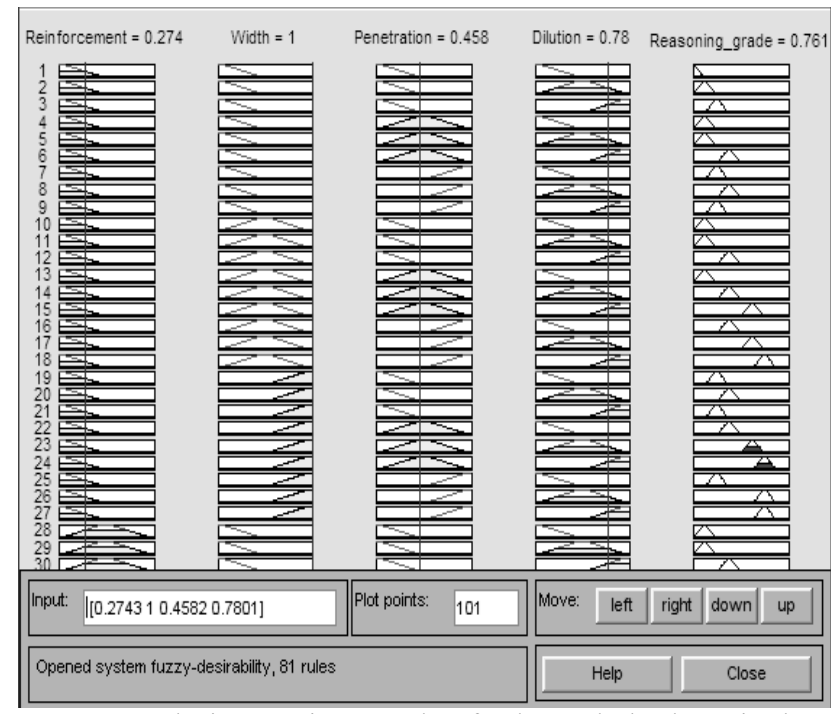

Fig. 8. Fuzzy logic reasoning procedure for the results by the optimal Conditions
Table 5. Response table for fuzzy reasoning grade

\begin{tabular}{c|c|c|c|c|c}
\hline \multirow{2}{*}{$\begin{array}{c}\text { Welding } \\
\text { Parameters }\end{array}$} & \multirow{2}{*}{ Symbol } & \multicolumn{4}{|c}{ Fuzzy reasoning grade } \\
\cline { 3 - 6 } & & Level-1 & $\begin{array}{c}\text { Level- } \\
\mathbf{2}\end{array}$ & Level-3 & $\begin{array}{c}\text { Max- } \\
\text { Mini }\end{array}$ \\
\hline Current & I & 0.5843 & 0.5103 & 0.4063 & 0.178 \\
Voltage & V & 0.511 & 0.486 & 0.5035 & 0.025 \\
Speed & S & 0.537 & 0.519 & 0.444 & 0.093 \\
Stickout & E & 0.636 & 0.504 & 0.3608 & 0.275 \\
\hline \multicolumn{4}{c}{ Total mean of the fuzzy reasoning grade $=0.503$}
\end{tabular}

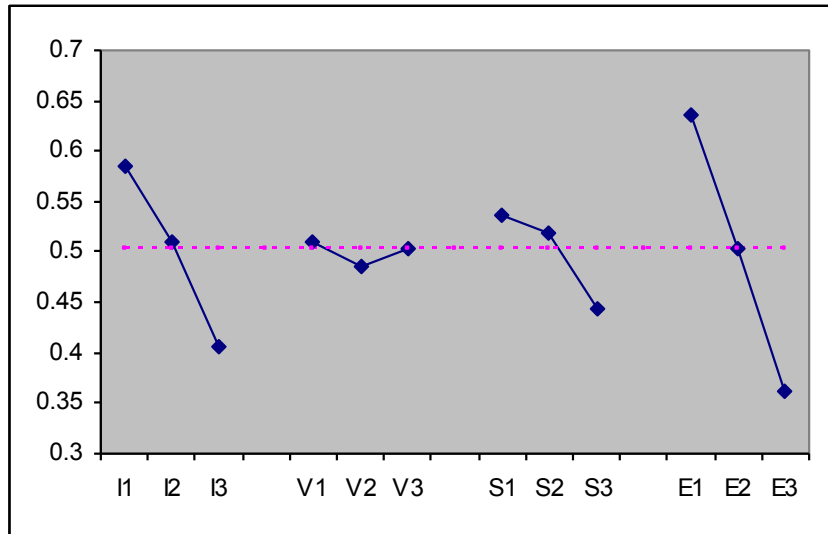

Fig. 9. Response graph for fuzzy reasoning grade

\subsection{Analysis Of Variance (ANOVA)}

ANOVA is performed to identify the process parameters of submerged arc welding that significantly affect the multiple performance characteristics. An ANOVA table consists of sums of squares, corresponding degrees of freedom, the Fratios corresponding to the ratios of two mean squares, and the contribution proportions from each of the control factors. These contribution proportions can be used to assess the importance of each factor for the interested multiple performance characteristic. The result of ANOVA for multiple quality characteristics (Table 6) shows that electrode stickout is the most significant control factor followed by welding current. The percentage contribution of each control factor to the total variance is electrode stickout $56.88 \%$, welding current $24.00 \%$, welding speed $8.2 \%$ and arc voltage $0.05 \%$. Here, arc voltage and welding speed have been found to be an insignificant factor in influencing the overall fuzzy reasoning grade.

Table 6. Results from ANOVA

\begin{tabular}{l|l|l|l|l|l|l}
\hline Factors & $\begin{array}{l}\text { Degrees } \\
\text { of } \\
\text { Freedom }\end{array}$ & $\begin{array}{l}\text { Sum of } \\
\text { Squares }\end{array}$ & $\begin{array}{l}\text { Mean } \\
\text { Squares }\end{array}$ & $\begin{array}{l}\text { F } \\
\text { value }\end{array}$ & $\begin{array}{l}\mathbf{P} \\
\text { value }\end{array}$ & $\begin{array}{l}\text { Contribution } \\
\%\end{array}$ \\
\hline I & 2 & 0.143928 & 0.071964 & 18.99 & 0.000 & 24 \\
V & 2 & 0.003054 & 0.001527 & 0.40 & 0.674 & 0.5 \\
S & 2 & 0.043346 & 0.021673 & 5.72 & 0.012 & 8.2 \\
E & 2 & 0.341044 & 0.170522 & 45.00 & 0.000 & 56.88 \\
Error & 18 & 0.068212 & 0.003790 & - & - & 11.37 \\
Total & 26 & 0.599584 & - & - & - & 100.00 \\
\hline
\end{tabular}

\subsection{Confirmation Test}

Confirmation test is crucial step recommended by Taguchi to verify experimental conclusion. Three sets of test were conducted to verify the bead geometries and dilution at optimum level of $I_{1} V_{1} S_{1} E_{1}$ and the average values obtained for bead reinforcement, bead width, bead penetration and dilution are $1.19 \mathrm{~mm}, 15.46 \mathrm{~mm}, 4.15 \mathrm{~mm}$ and $15.68 \%$ respectively. The results were within $95 \%$ confidence interval of predicted optimal value of selected parameters. The estimated fuzzy reasoning grade $\hat{\gamma}$ using the optimal 
level of the welding parameters is calculated using Equation (7).

$$
\left.\hat{\gamma}=\gamma_{m}+\sum_{i=1}^{q} \overline{\left(\gamma_{i}\right.}-\gamma_{m}\right)
$$

where $\gamma_{m}$ is the total mean of the fuzzy reasoning grade,

$\gamma_{i}$ is the mean of the fuzzy reasoning grade at the optimal level, and $q$ is the number of the welding parameters that significantly affects the multiple performance characteristics. The estimated fuzzy reasoning grade is increased from 0.606 to 0.751 . Also it is observed that optimal design obtained from the desirability- fuzzy logic analysis has the largest experiential and predicted fuzzy reasoning grade with $\mathrm{R}^{2}$ value of 0.8713 . It is clearly shown that the multiple objectives of the weld process are together improved remarkably.
In the present work, experiments are carried out to collect the data using Taguchi $\mathrm{L}_{27}$ orthogonal array design. The hybrid, fuzzy- desirability technique has been introduced to optimize the multiple properties of submerged arc welding in SA516 Gr. 70 steel. In this approach, since the responses are Linguistic in nature it is not essential to check interdependence (correlation) of the responses. Moreover the individual priority weights need not to be assigned. Fuzzy inference system takes care of that. From this analysis, it is revealed that electrode stickout and welding current are predominant factors which affect the weld quality of SA516 Gr. 70 steel. The best performance characteristics are obtained with an optimum parameter setting of $I_{1} V_{1} S_{1} E_{1}$. Confirmation test proved that the determined optimum condition of welding parameters satisfy the real requirement. It is found that the proposed procedure employed in this study can resolve a complex parameter design problem with multiple responses. It could be applied to those areas where there are large data sets and a number of responses are to be optimized simultaneously.

\section{Conclusion}

\section{References}

1. Chandel, R.S.; Seow, H.P.; Cheong, F.L.: Effect of increasing deposition rate on the bead geometry of submerged arc welds. Journal of Materials Processing Technology. 72,124-128 (1999).

2. Houldcroft, P.T.: Submerged-Arc Welding. Woodhead Publishing Ltd. England, (1989).

3. Welding Handbook. American Welding Society, 2 (1978).

4. Saurav Datta; Goutam Nandi; Asish Bandyopadhyay; Pradip Kumar Pal.: Application of PCA-based hybrid Taguchi method for correlated multicriteria optimization of submerged arc weld: a case study. Int J Adv Manuf Technol. 45, 276-286 (2009).

5. Toyofumi, K.; Hirotaka, N.W.; Yukio, N.; Katsuyuki, S.: Optimization of welding materials and conditions for high speed submerged arc welding of spiral pipe. Transactions of the Iron and Steel Institute of Japan. 26(5), 439-444 (1986).

6. Tsai, H. L.; Tarng, Y.S.; Tseng, C.M.: Optimization of submerged arc welding process parameters in hardfacing. International Journal of Advanced Manufacturing Technology. 12, 402- 406 (1996).

7. Tarng, Y. S.; Yang, W.H.: Application of the Taguchi Method to the Optimization of the Submerged Arc Welding Process. Materials and Manufacturing Processes. 13 (3), 455-467 (1998).

8. Gunaraj, V.; Murugan, N.: Application of response surface methodology for predicting weld bead quality in submerged arc welding of pipes. Journal of Materials Processing and Technology. 88(1), 266-275 (1999).

9. Keshav Prasad; Dwivedi, D.K.: Microstructure and Tensile Properties of Submerged Arc Welded 1.25Cr-0.5Mo Steel Joints. Materials and Manufacturing Processes. 23 (5), 463-468 (2008.)

10. Yang, L.J.; Chandel, R.S.: An analysis of curvilinear regression equations for modeling the submerged-arc welding process. Journal of Materials Processing and Technology. 37, 601-611 (1993).

11. Yang, L.J.; Bibby, M.J.; Chandel, R.S.: Linear regression equations for modeling the submerged arc welds. Journal of Materials Processing and Technology. 39, 33- 42 (1993).

12. Lee, J. L.; Rhee, S.: Prediction of process parameters for gas metal arc welding by multiple regression analysis. Proceedings of Institution of Mechanical Engineers - B. 14, 443-449 (2000).

13. Deng, J.: Introduction to grey system. The Journal of Grey System. 1, 1-24 (1989).

14. Tarng, Y. S.; Juang, S.C.; Chang, C.H.: The use of grey based Taguchi methods to determine submerged arc welding process parameters in hardfacing. Journal of Materials Processing Technology. 128, 1-6 (2002)

15. Biswas, A.; Bhaumik, S.; Majumdar, G.; Saurav Datta; Mahapatra, S.S.: Bead Geometry Optimization of Submerged Arc Weld: Exploration of Weighted Principal Component Analysis (WPCA). Applied Mechanics and Materials. 110, 790-798. (2011).
16. Ankita Singh; Saurav Datta; Siba Sankar Mahapatra; Tapan Singha; Gautam Majumdar.: Optimization of bead geometry of submerged arc weld using fuzzy based desirability function approach. J Intell Manuf. DOI 10.1007/s10845-011-0535-3.

17. Coniglio, N.; Cross, C. E.; Michael, T.; Lammers, M.: Defining a Critical Weld Dilution to Avoid Solidification Cracking in Aluminum. Welding Journal. 87, 237-247(2008)

18. John Deb Barma, S.C.; Joydeep Roy; Saha, B.: Process Parametric Optimization of Submerged Arc Welding by Using Utility Based Taguchi Concept. Advanced Materials Research. 1194, 488-489 (2012).

19. Naveen Sait, A.; Aravindan, S.; Noorul Haq, A.: Optimisation of machining parameters of glass-fibre-reinforced plastic (GFRP) pipes by desirability function analysis using Taguchi technique. Int J Adv Manuf Technol. 43, 581-589 (2009).

20. Amar Patnaik, S.S.; Biswas, S.; Mahapatra.: An evolutionary approach to parameter optimisation of submerged arc welding in the hardfacing process. Int. J. Manuf. Res. 2, 462-483 (2007).

21. Siva, K.; Murugan, N.; Logesh, R.: Optimization of weld bead geometry in plasma transferred arc hardfaced austenitic stainless steel plates using genetic algorithm. Int. J. Adv. Manuf. Technol. 41, 24-30 (2009).

22. Baskar, N.; Asokan, P.; Saravanan, R.; Prabhaharan, G.: Optimization of machining parameters for milling operations using non-conventional methods. Int. J. Adv. Manuf. Technol, 25, 10781088 (2005).

23. Kumaresh Babu, S.P.; Natarajan, S.: Corrosion Behavior of Pulsed Gas Tungsten Arc Weldments in Power Plant Carbon Steel. Journal of Materials Engineering and Performance. 16, 620-625 (2007).

24. Lin, C. L.; Lin, J. L.; Ko, T. C.: Optimisation of the EDM Process Based on the Orthogonal Array with Fuzzy Logic and Grey Relational Analysis Method. Int J Adv Manuf Technol. 19, 271277(2002).

25. Harrington, E.C.: The desirability function. Industrial Quality Control.21, 494-498 (1965).

26. Kim, K.J.; Lin, D.K.J.: Simultaneous optimization of mechanical properties of steel by polynomial regression functions. Appl. Stat. 49, 311-325 (2000).

27. Derringer, G.; Suich, R.: Simultaneous optimization of several response variables. Journal of Quality Technology. 12, 214-219 (1980).

28. Datta, S.; Bandyopadhyay, A.; Pal, P. K.: Desirability function approach for solving multi-objective optimization problem in submerged arc welding. International Journal for Manufacturing Science and Production. 7(2), 127-135 (2006).

29. Zadeh, L.: Fuzzy sets Information Control. 8, 338-353 (1965). 
30. Zimmermann, H.J.: Applications of fuzzy sets theory to mathematical programming. Information Sciences. 36, 29-58 (1985)

31. Didier Dubois; Henri Prade: Fuzzy sets and systems: Theory and applications.American Mathematical society. 7(3), 603-612(1982).

32. Chiang, K.T.; Liu, N.M.; Chou, C.C.: Machining parameter optimization on the die casting process of magnesium alloy using the grey-based fuzzy algorithm. International Journal of Advanced Manufacturing Technology. 38, 229-237 (2008).

33. Ahilan, C.; Kumanan, S.; Sivakumaran, N.: Multi objective optimization of $\mathrm{CNC}$ turning process using grey based fuzzy logic. International Journal of Machining and Machinability of materials. 5(4),434-451 (2009). 